\title{
Editorial
}

Nephrology

Published online: January 21, 2020

DOI: $10.1159 / 000505738$

\section{Membranous Nephropathy Due to Anti-GBM Antibodies of Mice and Men}

\author{
Richard J. Glassock \\ Geffen School of Medicine at UCLA, Los Angeles, CA, USA
}

The characteristic glomerular lesion seen in anti-glomerular basement membrane (aGBM)-induced nephritis is exuberant crescent formation accompanied by ultralinear deposits of IgG [1]. However, rarely a lesion of membranous nephropathy $(\mathrm{MN})$ with granular, sub-epithelial deposits of IgG can be observed, a phenomenon first described almost 45 years ago by Agodoa et al. [2]. Since then a small number of cases of aGBM coexisting with a lesion of $\mathrm{MN}$ have been described [3-5]. In addition, classical primary $\mathrm{MN}$ due to anti-phospholipase A2 receptor autoantibodies can be complicated by crescent formation (in about $5 \%$ of cases), in the absence of aGBM antibodies [5]. Typically, the cases of isolated non-crescentic MN associated with aGBM have been anti-phospholipase A2 receptor negative $[3,5]$.

The precise nature of the autoimmune response and the target antigen in the uncommon $\mathrm{MN}$ variant of aGBM disease has been a mystery. Several plausible hypotheses have been advanced, largely consequent to studies in experimental animals (particularly the DBA/1, DBA/2, and WKY strains of inbred mice susceptible to production of autoimmune glomerulonephritis). These proposed mechanisms include (1) rearrangement of the immune complexes formed in the sub-epithelial spaces to form visible lattices $[6,7] ;(2)$ unique target antigens within the COLIV alpha $3 \mathrm{NC1}$ domain allowing for formation of discrete sub-epithelial immune deposits in situ [8]; or (3) intermolecular epitope spreading or changes in antibody subclass following intensive immu-

\section{KARGER}

(C) 2020 S. Karger AG, Basel

E-Mail karger@karger.com

www.karger.com/ajn nization schedules [8]. Very clearly differences exist in susceptibility among inbred mouse strains to aGBM antibody-induced nephritis [9]. Both crescentic GN with linear deposits of IgG and MN with granular deposits of IgG can be produced by immunizations with heterologous COLIV alpha $3 \mathrm{NC1}$ domain, mostly in the DBA line of inbred mice. These lesions can occur sequentially (linear IgG deposit first, granular deposits later) or as isolated crescentic nephritis or $\mathrm{MN}$, depending on the inbred strain used and the immunization schedule employed [10].

The epitopes involved in the production of an isolated form of $\mathrm{MN}$ induced by immunization with human COLIV alpha $3 \mathrm{NC1}$ domain antigen has been elegantly explored by Wang et al. [11] in a paper published in this issue of the American Journal of Nephrology. The investigators synthesized 24 linear peptides spanning the entire human COLIV alpha 3 NC 1 domains, including those typically involved in the production of aGBM autoantibody in human disease (sometimes called Goodpasture's disease). Male DBA/1 mice were immunized with these peptides in complete Freund's adjuvant. Eighty-three percent of mice immunized with the intact human COLIV alpha $3 \mathrm{NC1}$ domain (positive control) and 50\% of those immunized with a 14 mer peptide 23 (Alpha $3_{141-154}$ ) developed proteinuria and a typical lesion of $\mathrm{MN}$ with granular deposits of mouse IgG1 (equivalent to IgG4 in humans). Crescent formation was not observed in the positive control
Richard J. Glassock, MD 8 Bethany Laguna Niguel, CA 92677 (USA)

E-Mail rjglassock@gmail.com 
or in the Peptide 23 immunized mice. Interestingly, the mice immunized with Peptide 23 and who developed MN had anti-P23 antibodies of comparable levels to those who were immunized with the Peptide 23 but who did not develop a $\mathrm{MN}$ lesion or proteinuria, indicating the possibility that another non-aGBM antibody or a requirement for a "second hit" might be involved in disease pathogenesis. The mice immunized with the remaining COLIV alpha 3-derived peptides developed peptide-specific antibodies but did not develop proteinuria or MN lesions.

These findings clearly implicate the 14 amino acid linear Peptide 23 as containing the immunogenic epitope responsible for $\mathrm{MN}$ in DBA/1 mice immunized with COLIV alpha $3 \mathrm{NC} 1$ domain, but they do not define the precise molecular configuration of the dominant immunogenic epitope. They also contrast with the findings of Hopfer et al. [10] in a similar model of $\mathrm{MN}$ induced in DBA/1 mice by immunization with homologous (mouse) recombinant COLIV alpha 3 NCI domain-derived peptides, which implicated a 14 mer Peptide 71, having an entirely different linear amino acid sequence compared to the human COLIV alpha 3 NCI domain P23 used in the Wang et al. [11] study. Hopfer et al. [10] postulated the involvement of pathogenic auto-reactive $\mathrm{T}$-cell in the pathogenesis of the disease, an aspect not studied in the Wang et al. [11] experiments. Perhaps, this has much to do with the source of the antigens and the immunization schedule employed.

Notably, the COLIV alpha 3 Peptide 14, which causes crescentic aGBM disease in WKY mice, did not induce either crescentic or $\mathrm{MN}$ lesion in DBA/1 mice. Very clearly then the genetic repertoire of the DBA/1 mouse is an obligate requirement for the induction of an $\mathrm{MN}$ lesion by the Peptide 23. Further, the magnitude of the humoral immune response did not seem to predict the occurrence of MN, implying that other factors or "hits" are involved in pathogenesis, perhaps concomitant Tcell mediated or other antigen - antibody systems not included in this analysis. The COLIV alpha 3 chains are known to be synthesized by visceral epithelia cells (Podocytes) and are secreted into the extracellular milieu of the sub-epithelial space where they ultimately bind to integrins and are assimilated into the structure of the external lamina of the GBM. Theoretically, the COLIV alpha 3 NCI domains might be vulnerable to the formation of in situ immune complexes which can thence grow by lattice formation into visible sub-epithelial immune aggregates, typical of the MN lesion. The precise nature of the antigen contained within the sub-epithelial deposits in the DBA/1 model immunized with Peptide 23 was not explored. In addition, the IgG subclass (mouse IgG1 equivalent to human IgG4) may have been involved in the predilection to formation of an MN lesion instead of crescentic lesions, as has been suggested by Zhang et al. [8]. DBA/1 mice were used exclusively in the Wang et al. [11] study. DBA/2 mice are also sensitive to the production of glomerular lesions (crescents), with a linear to granular sequence for the arrangement of the deposits [12]. Further studies employing the DBA/2 mouse having an entirely different major histocompatibility genomic repertoire compared to the DBA1 mouse seem warranted.

The relevance of these intriguing findings to human disease is uncertain, but they do suggest that individuals that recapitulate the immune repertoire of the DBA/1 rather than the WKY mouse might be more susceptible to the MN lesion upon exposure to the Peptide 23 in an autoimmunogenic form. Further work is required to decipher the pathways involved, but this novel study provides very interesting insights into the possible pathogenic pathways involved in the uncommon form of $\mathrm{MN}$ due to aGBM disease.

\section{Disclosure Statement}

The author have no conflict of interest to disclose.

\section{References}

1 McAdoo SP, Pusey CD. Anti-Glomerular Basement Membrane Disease. Clin J Am Soc Nephrol. 2017 Jul;12(7):1162-72.

2 Agodoa LC, Striker GE, George CR, Glassock R, Quadracci LJ. The appearance of nonlinear deposits of immunoglobulins in Goodpasture's syndrome. Am J Med. 1976 Sep;61(3):407-13.

3 Segelmark M, Hellmark T. Anti-glomerular basement membrane disease: an update on sub-

MN Due to aGBM Antibodies of Mice and Men groups, pathogenesis and therapies. Nephrol Dial Transplant. 2019 Nov;34(11):1826-32.

4 Wang J, Zhu P, Cui Z, Qu Z, Zhang YM, Wang F, et al. Clinical Features and Outcomes in Patients With Membranous Nephropathy and Crescent Formation. Medicine (Baltimore). 2015 Dec;94(50):e2294.

5 Jia XY, Hu SY, Chen JL, Qu Z, Liu G, Cui Z, et al. The clinical and immunological features of patients with combined anti-glomerular basement membrane disease and membranous nephropathy. Kidney Int. 2014 Apr; 85(4):945-52.

6 Agodoa LY, Gauthier VJ, Mannik M. Antibody localization in the glomerular basement membrane may precede in situ immune deposit formation in rat glomeruli. J Immunol. 1985 Feb;134(2):880-4. 
7 Mannik M, Agodoa LY, David KA. Rearrangementofimmunecomplexesinglomerulileadsto persistence and development of electron-dense deposits.JExp Med. 1983 May;157(5):1516-28.

8 Zhang JJ, Malekpour M, Luo W, Ge L, Olaru F, Wang XP, et al. Murine membranous nephropathy: immunization with $\alpha 3$ (IV) collagen fragment induces subepithelial immune complexes and $\mathrm{F} c \gamma \mathrm{R}$-independent nephrotic syndrome. J Immunol. 2012 Apr;188(7):3268-77.
9 Reynolds J. Strain differences and the genetic basis of experimental autoimmune anti-glomerular basement membrane glomerulonephritis. Int J Exp Pathol. 2011 Jun;92(3):211-7.

10 Hopfer H, Hünemörder S, Treder J, Turner JE, Paust HJ, Meyer-Schwesinger C, et al. Glomerulopathy induced by immunization with a peptide derived from the goodpasture antigen a3IV-NC1. J Immunol. 2015 Apr;194(8): 3646-55.
11 Wang J, Wang M, Cui Z, Zhao MH. Epitope mapping of human a3(IV)NC1-induced membranous nephropathy in mice. Am J Nephrol. 2020, DOI: 10.1159/000505443.

12 Sutmuller M, Ekstijn GL, Ouellette S, De Heer E, Bruijn JA. Non-MHC genes determine the development of lupus nephritis in $\mathrm{H}-2$ identical mouse strains. Clin Exp Immunol. 1996 Nov;106(2):26572. 